Trusts that relate to Individual Funding Review (IFR) cases. Each of these requests has considerable resource implications and means that what would have been allocated for patient care is being spent on bureaucratic processes.

Whilst we totally support the arguments behind the need for an FoI, its original purpose was to help ensure public accountability in decision making. It was not designed to help achieve an improved response rate for a particular research project, the value of which could be challenged.

We would suggest that those overseeing postgraduate projects ensure that when reviewing the methodology adopted for research it specifically excludes the use of the FoI Act as an instrument to try and improve response rates.

P. Batchelor, A. Crosse, J. Donaghy, S. White Thames Valley Dental Public Health Network

DOI: 10.1038/sj.bdj.2011.827

\section{JUST ANOTHER NUMBER?}

Sir, 'time is money'. Nowhere else, it seems, is this phrase more poignant than in the NHS. Dentists, doctors and all other health professionals working for the NHS are restricted to strict targets, quotas and time limits. The very nature of having a suggested time limit for patient treatment/consultation leads to NHS dentists having very little time left (after taking medical history, diagnosing the problem, note taking and treatment) to spend on helping the patient on a more personal level. Although I am only a dental applicant, and have not yet started dental school, my work experience from a third-party perspective has raised some questions regarding dentist/patient relationships, and the contrast between this relationship in private and NHS practices. Does this in-and-out regime that many NHS dentists are forced to work under cause patients to believe they are just 'another number' on their dentist's ever-growing list? My opinion is that this lack of time to spend with patients contributes to many patients' bad attitudes in the surgery. I was quite taken aback by the difference in respect given towards dentists in NHS and private practices, and it led me to consider whether the patient-dentist relationship (or lack thereof) was the deciding factor. Perfectly polite people become bad-mannered and short when on the phone to an operator in a call centre. Why? Because they know they are just another number on the operator's list, and once their conversation is over, they move on to the next number down. The person on the other end then goes back to their business.

This shares some parallels with the NHS dental access centres. The patient comes in, receives their treatment and leaves as the next patient is ushered in. Although it is true that the dentist has many other patients to see, connecting with the patient and improving their experience is of great importance to all dentists, and of highest priority is patient care. In private practice, where the time restrictions are independently set, the dentist-patient relationship seems to be far better, particularly with the 'regulars'; they feel they know their dentist, and the dentist knows them. It seems that neither party benefits from the stringent time restrictions during the appointment, but then is time a luxury the NHS cannot afford for better patient satisfaction?

R. Harlow, Bedfordshire DOI: 10.1038/sj.bdj.2011.828

\section{SPHERICAL GREY VESICLES}

Sir, herpetic gingivostomatitis is an infection of the oral cavity caused by herpes simplex virus type 1 (HSV-type 1). Although this infection is often seen in infants and children younger than six years of age, it can also be seen in adults. ${ }^{1}$ Recurrent infection is commonly seen in adults due to various stimuli like sunlight, trauma, fever and stress. Recurrent infection has also been seen after initiation of dental treatment. ${ }^{2}$ A female patient aged 45 years reported to the Department of Periodontics complaining of tartar on her teeth (Fig. 1). Oral prophylaxis was initiated using hand instruments and the patient was recalled three days later for further scaling. At the recall visit she complained of pain in the labial and buccal gingiva of the lower arch.
Discrete, spherical grey vesicles were noticed on the gingiva (Fig. 2) and she complained of a sore throat with tender and palpable submandibular lymph nodes. Based on the history and clinical examination a diagnosis of acute herpetic gingivostomatitis was made. The antiviral drug acyclovir was given for five days and palliative treatment included lignocaine gel and the analgesic drug paracetamol. The case serves as a reminder that age, although it may make a diagnosis seem implausible, does not alone exclude it. ${ }^{3}$

R. Singh, S. R. Srinivas, K. D. Jithendra India

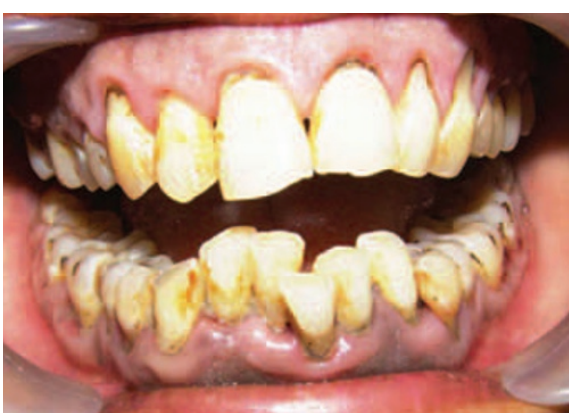

Fig. 1 Clinical image before initiation of scaling

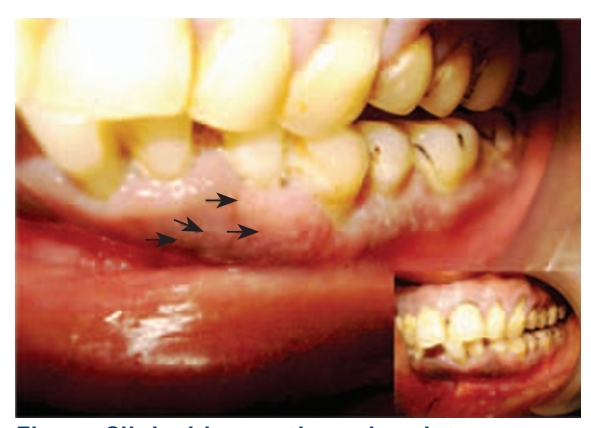

Fig. 2 Clinical image three days later, arrows point to the presence of discrete, spherical gray vesicles on the gingiva

1. Chauvin P J, Ajar A H. Acute herpetic gingivostomatitis in adults: a review of 13 cases, including diagnosis and management. J Can Dent Assoc 2002; 68: 247-251.

2. Williamson R T. Diagnosis and management of recurrent herpes simplex induced by fixed prosthodontic tissue management: a clinical report. J Prosthet Dent 1999; 82: 1-2.

3. MacPhail L, Greenspan D. Herpetic gingivostomatitis in a 70-year-old man. Oral Surg Oral Med Oral Pathol Oral Radiol Endod 1995; 79: 50-52.

DOI: 10.1038/sj.bdj.2011.829 